\title{
tAnGo: a randomised phase III trial of gemcitabine in paclitaxel-containing, epirubicin/cyclophosphamide-based, adjuvant chemotherapy for early breast cancer: a prospective pulmonary, cardiac and hepatic function evaluation
}

\author{
AM Wardley*,1, L Hiller², HC Howard ${ }^{3}$, JA Dunn², A Bowman ${ }^{4}$, RE Coleman ${ }^{5}$, IN Fernando ${ }^{6}$, DM Ritchie ${ }^{7}$, \\ $\mathrm{HM} \mathrm{Earl}^{\mathbf{8}}$ and CJ Poole ${ }^{3}$ on behalf of the tAnGo trial collaborators \\ 'CR UK Department of Medical Oncology, Christie Hospital, Manchester M20 4BX, UK; ${ }^{2}$ Warwick Medical School Clinical Trials Unit, University of \\ Warwick, Coventry CV4 7AL, UK; ${ }^{3}$ Cancer Research UK Clinical Trials Unit, University of Birmingham, Birmingham BI5 2 TT, UK; ${ }^{4}$ Edinburgh Cancer \\ Centre, Western General Hospital, Edinburgh EH4 2XU, UK; ${ }^{5}$ Cancer Research Centre, Weston Park Hospital, Sheffield SI 0 2SJ, UK; ${ }^{6}$ Cancer Centre, \\ Queen Elizabeth Hospital, Birmingham B 5 2TH, UK; ${ }^{7}$ Beatson Oncology Centre, Western Infirmary, Glasgow GII 6NT, UK; ${ }^{8}$ Oncology Centre, \\ Addenbrookes Hospital, University of Cambridge, Cambridge CB2 OQQ, UK
}

\begin{abstract}
tAnGo is a large randomised trial assessing the addition of gemcitabine(G) to paclitaxel(T), following epirubicin(E) and cyclophosphamide $(C)$ in women with invasive higher risk early breast cancer. To assess the safety and tolerability of adding $\mathrm{G}$, a detailed safety substudy was undertaken. A total of 135 patients had cardiac, pulmonary and hepatic function assessed at (i) randomisation, (ii) mid-chemotherapy, (iii) immediately post-chemotherapy and (iv) 6 months post-chemotherapy. Skin toxicity was assessed during radiotherapy. No differences were detected in FEV, or FVC levels between treatment arms or time points. Diffusion capacity $\left(T L_{C O}\right)$ reduced during treatment $(P<0.0001)$, with a significantly lower drop in EC-GT patients $(P=0.02)$. Most of the reduction occurred during EC and recovered by 6 -months post treatment. There was no difference in cardiac function between treatment arms. Only II patients had echocardiography/MUGA results change from normal to abnormal during treatment, with only five having LVEF $<50 \%$. Transient transaminitis occurred in both treatment arms with significantly more in EC-GT patients postchemotherapy (AST $P=0.03, A L T P=0.003$ ), although the majority was low grade. There was no correlation between transaminitis and other toxicities. Both treatment regimens reported temporary reductions in pulmonary functions and transient transaminitis levels. Despite these being greater with EC-GT, both regimens appear well tolerated.
\end{abstract}

British Journal of Cancer (2008) 99, 597-603. doi:I0.1038/sj.bjc.6604538 www.bjcancer.com

Published online 29 July 2008

(c) 2008 Cancer Research UK

Keywords: breast cancer; adjuvant chemotherapy; pulmonary; toxicity

Breast cancer deaths in the UK have declined $20-30 \%$ since the late 1980s, despite an increasing incidence (41720 new cases diagnosed in 2002). Increased use and improvement in systemic adjuvant therapy have undoubtedly contributed to this reduced mortality in the face of increasing incidence.

Combination chemotherapy has been shown to reduce recurrence rates when given after surgery to women at risk of relapse. Anthracycline-based regimens are the standard of care throughout the developed world reducing the breast cancer death rate ratios by $26-45 \%$ for younger and $17-24 \%$ for older women (EBCTCG, 2005). Modern anthracycline regimens appear to offer greater improvement $(\sim 30 \%$ reduction in hazard ratio) over CMF (Levine

\footnotetext{
* Correspondence: Dr AM Wardley, Department of Medical Oncology, Cancer Research UK, Christie Hospital, 550 Wilmslow Road, Manchester M20 4BX, UK. E-mail: Andrew.Wardley@christie.nhs.uk

Received I 4 February 2008; revised 23 May 2008; accepted 2 July 2008; published online 29 July 2008
}

et al, 2005; Poole et al, 2006a). Block sequential chemotherapy regimens have become standard in breast cancer after the demonstration that sequence and timing were important (Bonadonna et al, 2004).

The 1990s saw the initiation of many large randomised controlled trials of taxanes in the adjuvant therapy of breast cancer. Results from four first generation taxane trials are available and have resulted in licensing of taxanes for the adjuvant treatment of nodepositive breast cancer. The addition of four cycles of paclitaxel after four cycles of doxorubicin and cyclophosphamide reduces the risk of recurrence by $17 \%$, with manageable toxicity (Henderson et al, 2003; Mamounas et al, 2003), and became standard of care in the US in the late 1990s, for higher risk node-positive patients.

Based on pre-clinical evidence of a potentially favourable interaction between paclitaxel and gemcitabine (Kroep et al, 1999), as well as encouraging activity for gemcitabine in advanced breast cancer (Carmichael et al, 1995; Blackstein et al, 1997; Spielmann et al, 1997; Sanchez et al, 1998; Akrivakis et al, 1999; Colomer et al, 2000), the tAnGo trial was initiated in the year 2000 
to test the addition of gemcitabine to block sequential anthracycline and paclitaxel adjuvant chemotherapy. The trial compared EC-GT (four cycles of epirubicin $90 \mathrm{mg} \mathrm{m}^{-2}$ and cyclophosphamide $600 \mathrm{mg} \mathrm{m}^{-2}$ day 1 every (q) 3 weeks, followed by four cycles of paclitaxel $175 \mathrm{mg} \mathrm{m}^{-2}$ every $3 \mathrm{~h}$ infusion day 1 and gemcitabine $1250 \mathrm{mg} \mathrm{m}^{-2}$ days 1 and $8 \mathrm{q} 3$ weeks) with EC-T. The primary end point for the 3000 patient trial was disease-free survival (DFS), aiming to prove a $5 \%$ improvement from $70 \% 5$-year DFS.

In view of the unknown acute and long-term sequelae of gemcitabine in combination with paclitaxel, radiation-sensitisation properties of gemcitabine (McGinn et al, 1996) and concern about the possibility of severe and/or delayed pulmonary (Gupta et al, 2002; Trodella et al, 2002; Maas et al, 2003) and hepatic toxicity (Poole et al, 2006b), a detailed toxicity and tolerability surveillance study was undertaken on an initial cohort of patients randomised into tAnGo. Hepatic, cardiac and pulmonary function and all adverse events (AEs) were monitored.

\section{PATIENTS AND METHODS}

All patients randomised into tAnGo were eligible for this detailed safety substudy (DSS) until the accrual target had been met. Patients underwent tests at four time points: (i) randomisation; (ii) mid-chemotherapy (between cycles 4 and 5); (iii) immediately post-chemotherapy and (iv) 6-months post-chemotherapy. Late toxicity assessment included follow-up tests in the event of any symptomatic deterioration, and also at 5 and 10 years posttreatment. Results from the first four planned time points are presented here.

Pulmonary function assessments comprised spirometry tests, Forced Expiratory Volume in one second ( $\mathrm{FEV}_{1}$, litres) as a measure of airway obstruction and Forced Vital Capacity (FVC, litres), single breath diffusion tests, measuring total lung capacity $\left(\mathrm{TL}_{\mathrm{CO}}, \mathrm{mmol} \mathrm{min}^{-1} \mathrm{kPa}^{-1}\right.$ ) (locally corrected for $\mathrm{Hb}$ ), and gas diffusion of $\mathrm{CO}$ within lungs $\left(\mathrm{K}_{\mathrm{CO}}, \mathrm{mmol} \mathrm{min}^{-1} \mathrm{kPa}^{-1} \mathrm{l}^{-1}\right)$. Cardiac assessments comprised ECG tests and either echocardiograms or MUGA (multi-gated acquisition) scans. Chest X-rays (CXR) were also undertaken, as were hepatic function tests serum AST and ALT. Radiotherapy acute skin toxicity treatment was collected weekly.

This trial was approved by Multi-Research Ethics Committee and conducted in accordance with the declaration of Helsinki.

\section{STATISTICAL METHODS}

Symptomatic pulmonary toxicity associated with single-agent gemcitabine was estimated to be $1.6 \%$ (Sara et al, 2000). Assuming a $1.5-2 \%$ incidence of symptomatic pulmonary toxicity, the accrual of 65 patients from each treatment arm into the tAnGo DSS would allow detection of a 10-fold difference in the risk of symptomatic pulmonary toxicity relative to this, with an $80 \%$ power at the 2-sided 5\% level of significance.

$\mathrm{FEV}_{1}$ levels were categorised into normal, mild, moderate or severe obstruction using British Thoracic Society's COPD guidelines. ECGs, echocardiograms, MUGA scans and CXRs were classed as normal or abnormal by clinicians. Hepatic function was graded according to CTC toxicity criteria (version 2). Radiotherapy acute skin toxicities were categorised by clinicians into nil, mild, moderate or severe. Assessment times and treatment arms were then compared using $\chi^{2}$ tests, Fisher's exact tests or generalised linear models where appropriate.

Random effects modelling was applied to $\mathrm{FVC}$ and $\mathrm{TL}_{\mathrm{CO}}$ levels over time, and results presented graphically as patients' raw scores, percentages of patients' baseline measures and the average patient values over time for each treatment arm as predicted by the model. Results were also categorised into low, normal or high levels (Quanjer, 1993).

\section{RESULTS}

A total of 135 tAnGo patients (69 randomised to EC-GT, 66 to EC-T) were entered into the DSS between August 2001 and October 2002. The DSS subgroup appeared balanced in terms of randomised treatment and also balanced across randomised treatment groups in terms of prognostic variables (Table 1). However, when comparing the DSS group with other patients randomised into tAnGo, the DSS group reported a smaller proportion of ER and PgR positive tumours, a larger proportion of HER2 positive tumours, higher nodal status, higher mastectomy rates and worse tumour grades. These expected differences reflect the change in tAnGo eligibility criteria, from ER-poor to any hormone status, which was implemented after the first 550 patients had been randomised, after the DSS had completed recruitment. DSS patients appear representative of breast cancer patients at large.

All 135 patients completed baseline assessments, with 117 (87\%) being assessed at all four time points. The completeness of individual tests at each assessment time is generally high, except for hepatic function tests, which were often overlooked, especially at later assessments (Table 2).

\section{Pulmonary function results}

Overall $88 \%$ of all $\mathrm{FEV}_{1}$ results were classed as normal (Figure 1). There was no indication in either treatment arm of a significant time effect on normal $\mathrm{FEV}_{1}$ levels $(P>0.57)$, nor any differences detected between treatments at each of the four time points $(P>0.23)$.

Eighty one percent of all FVC results were classed as normal (Figure 2A-C). In terms of the actual scores of the patients, there was no significant linear change over time $(P=0.55)$ and no difference between treatments in terms of their change over time $(P=0.84)$. Individually for the treatment arms, the populations' FVC scores, predicted from linear modelling, highlight the lack of differences over time and between treatments (Figure 2C).

A total of $56 \%$ of all $\mathrm{TL}_{\mathrm{CO}}$ results were classed as normal (Figure 2D-F). Individual patient scores show a slight reduction in $\mathrm{TL}_{\mathrm{CO}}$ during treatment, which appears slightly more pronounced in the EC-GT patients. The quadratic change over time observed $(P<0.0001)$ suggests that the reduced $\mathrm{TL}_{\mathrm{CO}}$ results during treatment tend to recover 6-months post treatment. The populations' $\mathrm{TL}_{\mathrm{CO}}$ scores, predicted from quadratic modelling, show a significantly lower drop in $\mathrm{TL}_{\mathrm{CO}}$ levels for EC-GT patients $(P=0.02)$ (Figure $2 \mathrm{~F}$ ).

Dyspnoea was recorded as an AE during treatment in $32 \%$ of patients (43 of 135) and 9\% of all cycles. Dyspnoea was CTC grade 2 in $89 \%$ and grade 3 in $4 \%$ of abnormal cycles. It was ungraded in the remaining $7 \%$.

One hundred and twenty-two of the 135 DSS patients (90\%) received radiotherapy, $13(10 \%)$ did not. 134 of the 135 DSS patients (99\%) have calculable chemotherapy course dose intensity. Adjusting the analysis of the pulmonary function tests by whether patients had received radiotherapy or not, and also by their chemotherapy dose intensity did not affect findings.

\section{Cardiac function}

Overall 370 ECG, 323 echocardiogram and 168 MUGA results have been reported. Two patients switched mode of assessment of LVEF from initial to subsequent assessments: one from MUGA to echo and one vice versa - neither of these patients had any suggestion of cardiac dysfunction therefore they have been included in the analysis.

The majority of patients have normal echocardiograms/MUGAs (96\% of patients at baseline, $97 \%$ at mid and $93 \%$ at end of 
Table I Patient and tumour characteristics

\begin{tabular}{|c|c|c|c|c|}
\hline & \multicolumn{2}{|c|}{$\operatorname{ECGT}(n=69)$} & \multicolumn{2}{|c|}{ ECT $(n=66)$} \\
\hline & $\mathbf{N}$ & $\%$ & $\mathbf{N}$ & $\%$ \\
\hline \multicolumn{5}{|l|}{ Age } \\
\hline$\leqslant 50$ years old & 38 & 55 & 36 & 55 \\
\hline$>50$ years old & 31 & 45 & 30 & 45 \\
\hline \multicolumn{5}{|l|}{ ER status } \\
\hline Negative & 56 & 81 & 53 & 80 \\
\hline Weakly-positive & 7 & 10 & 7 & 11 \\
\hline Positive & 6 & 9 & 6 & 9 \\
\hline \multicolumn{5}{|l|}{$P g R$ status } \\
\hline Negative & 43 & 62 & 34 & 52 \\
\hline Weakly-positive & 7 & 10 & 10 & 15 \\
\hline Positive & 2 & 3 & 2 & 3 \\
\hline Unknown & 17 & 25 & 20 & 30 \\
\hline \multicolumn{5}{|l|}{ Nodal status } \\
\hline Negative & 13 & 19 & 12 & 18 \\
\hline I-3 nodes positive & 24 & 35 & 24 & 36 \\
\hline$\geqslant 4$ nodes positive & 32 & 46 & 30 & 46 \\
\hline \multicolumn{5}{|l|}{ HER2 status } \\
\hline+++ & 11 & 16 & 9 & 14 \\
\hline Other $(0,1+, 2+)$ & 17 & 25 & 14 & 21 \\
\hline Not measured & 41 & 59 & 43 & 65 \\
\hline \multicolumn{5}{|l|}{ ECOG performance status } \\
\hline 0 & 64 & 93 & 63 & 95 \\
\hline I & 3 & 4 & 3 & 5 \\
\hline 2 & 2 & 3 & 0 & 0 \\
\hline \multicolumn{5}{|l|}{ Menopausal status } \\
\hline Pre & 33 & 48 & 27 & 41 \\
\hline Peri & 5 & 7 & 5 & 8 \\
\hline Post & 27 & 39 & 28 & 42 \\
\hline Hysterectomy & 2 & 3 & I & I \\
\hline Unknown & 2 & 3 & 5 & 8 \\
\hline \multicolumn{5}{|l|}{ Definitive surgery } \\
\hline Mastectomy & 45 & 65 & 42 & 64 \\
\hline Breast conserving surgery & 24 & 35 & 24 & 36 \\
\hline \multicolumn{5}{|l|}{ Definitive surgery to entry (days) } \\
\hline Median (IQR) & \multirow{2}{*}{\multicolumn{2}{|c|}{$\begin{array}{c}32(24-42) \\
11-57\end{array}$}} & \multirow{2}{*}{\multicolumn{2}{|c|}{$\begin{array}{c}33(2 \mid-39) \\
15-56\end{array}$}} \\
\hline Range & & & & \\
\hline \multicolumn{5}{|l|}{ Tumour diameter } \\
\hline$\leqslant 2 \mathrm{~cm}$ & 22 & 32 & 29 & 44 \\
\hline$>2$ and $\leqslant 5 \mathrm{~cm}$ & 36 & 52 & 32 & 48 \\
\hline$>5 \mathrm{~cm}$ & 9 & 13 & 4 & 6 \\
\hline Unknown & 2 & 3 & । & 2 \\
\hline \multicolumn{5}{|l|}{ Distance to closest radial margin } \\
\hline$<\mathrm{Imm}$ & 5 & 7 & 2 & 3 \\
\hline I to $<5 \mathrm{~mm}$ & 10 & 15 & 15 & 23 \\
\hline 5 to $<10 \mathrm{~mm}$ & 12 & 17 & 6 & 9 \\
\hline$\geqslant 10 \mathrm{~mm}$ & 17 & 25 & 16 & 24 \\
\hline Unknown & 25 & 36 & 27 & 41 \\
\hline \multicolumn{5}{|l|}{ Tumour type $\mathrm{e}^{\mathrm{a}}$} \\
\hline Ductal/NST & 63 & 91 & 61 & 92 \\
\hline Lobular & 9 & 13 & 4 & 6 \\
\hline Tubular/Cribform & I & I & 4 & 6 \\
\hline Medullary & I & I & I & I \\
\hline Other & । & 1 & 2 & 3 \\
\hline Unknown & । & । & 0 & 0 \\
\hline \multicolumn{5}{|l|}{ Tumour grade } \\
\hline I - Well differentiated & 0 & 0 & 1 & 2 \\
\hline 2 - Moderately differentiated & 6 & 9 & 5 & 7 \\
\hline
\end{tabular}

Table I (Continued)

\begin{tabular}{|c|c|c|c|c|}
\hline & \multicolumn{2}{|c|}{$\operatorname{ECGT}(n=69)$} & \multicolumn{2}{|c|}{$\mathrm{ECT}(n=66)$} \\
\hline & $N$ & $\%$ & $N$ & $\%$ \\
\hline 3 - Poorly differentiated & 63 & 91 & 59 & 89 \\
\hline Unknown & 0 & 0 & । & 2 \\
\hline \multicolumn{5}{|c|}{ Vascularllymphatic invasion reported } \\
\hline Yes & 48 & 70 & 36 & 55 \\
\hline No & 21 & 30 & 30 & 45 \\
\hline \multicolumn{5}{|l|}{ Axillary nodes involved } \\
\hline Median (IQR) & \multicolumn{2}{|c|}{$3(1-6)$} & \multicolumn{2}{|c|}{$3(1-9)$} \\
\hline Range & \multicolumn{2}{|c|}{$0-24$} & \\
\hline
\end{tabular}

${ }^{a}$ Some specimens have multiple types.

Table 2 Completeness of assessments

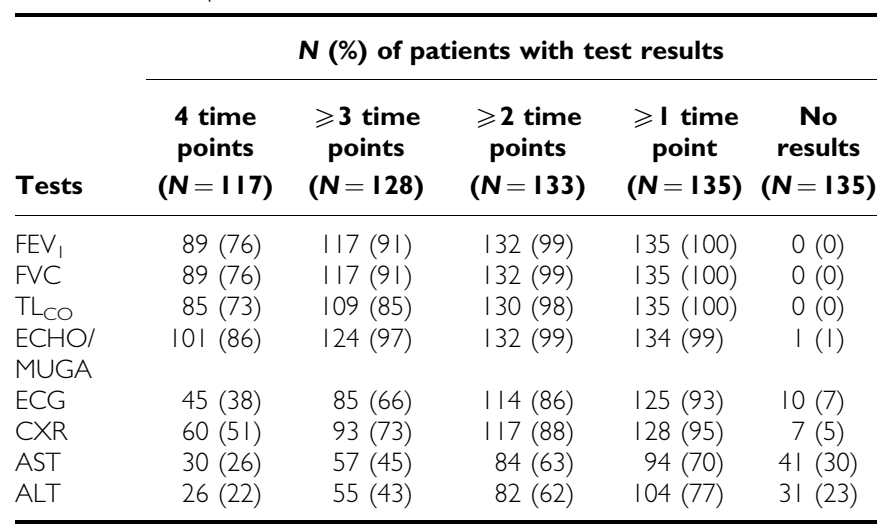

chemotherapy, $94 \%$ at 6 months) and ECG's (94\% of patients at baseline, $89 \%$ at mid and $96 \%$ at end of chemotherapy, $82 \%$ at 6 months (Figure $3 \mathrm{~A}$ and $\mathrm{B}$ ).

In $11(8 \%)$ patients (6 EC-T; 5 EC-GT), ECHO/MUGA's were categorised as having changed from normal to abnormal throughout treatment. In two patients (assessed by echocardiography) LVEF value was not recorded. Of the remaining nine patients, two increased LVEF by $2 \%$. For the other seven, the mean reduction in LVEF was 9\% (range: $2-16 \%$ ), with five patients having LVEF below $50 \%$. Four patients had a fall of LVEF $>10 \%$; in three of these to $<50 \%$. The first abnormal test was the second scan in three patients, the third in six patients and the fourth in two patients. Three cardiac SAE's were reported from two patients: one patient experienced tachycardia mid-chemotherapy, the other asymptomatic reduction in LVEF (54-42\%) mid-chemotherapy and symptomatic CHF 1 month later. Postchemotherapy, LVEF returned to normal after this patient was treated with the ACE inhibitor lisinopril. In 6 of 11 patients, cardiac function testing recovered to normal at 6-month post-chemotherapy. There was no significant change in ECHO/ MUGA cardiac function over time in either treatment arm $(P>0.41)$ and no difference between treatments at any time point $(P>0.36)$.

There was no difference in ECG results between treatments at any time point $(P>0.27)$ and no difference within either treatment arm over time $(P>0.12)$. The majority of the 34 possibly abnormal ECG's were minor ST-T wave changes (8), sinus brady/tachycardia (6), left bundle branch block (3) and left atrial abnormality (2). The ECG changed from normal to abnormal during treatment in 
only 15 patients (8 EC-T and 7 EC-GT). Only two of these had ECG changes suggestive of ischaemia, the others being minor ST-T or rhythm changes. Only one of these patients was deemed to have abnormal LVEF (55\% on the first two echocardiograms to $57 \%$ on the third, which was deemed to be abnormal and $52 \%$ on the fourth also abnormal). These data illustrate that
$\square$ Normal
- Moderate obstruction

- Mild obstruction - Severe obstruction

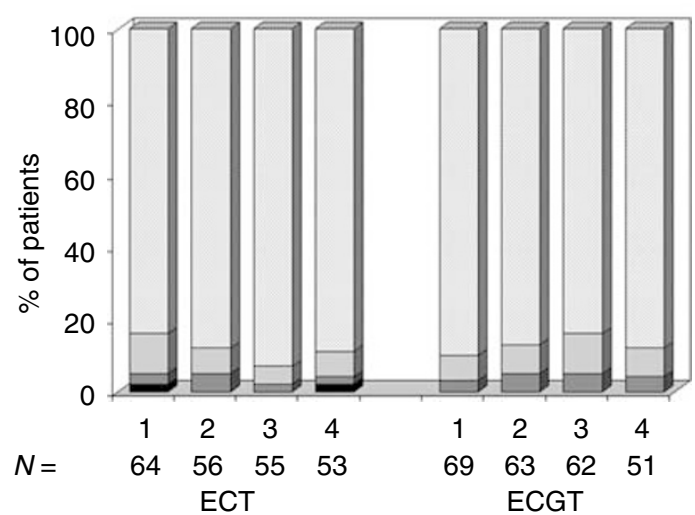

Figure I FEV, results over the four time points.
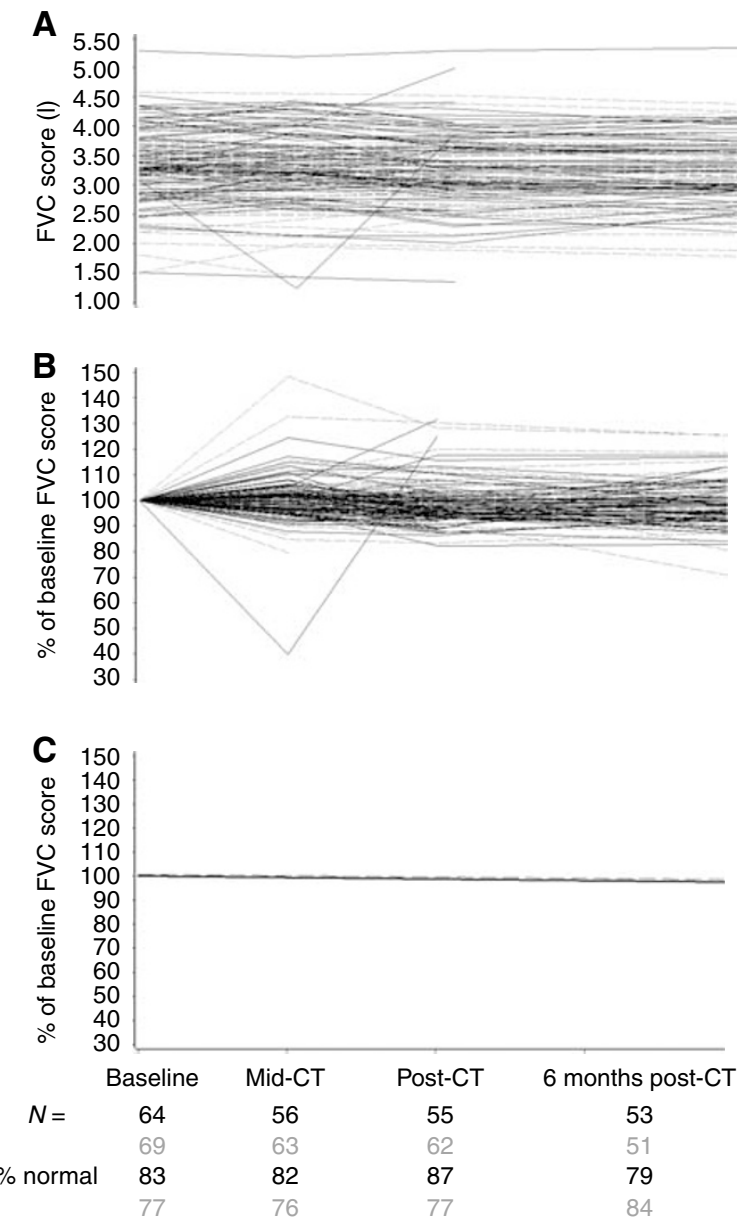

ECG's alone are not a very useful tool for assessing safety of chemotherapy.

At each time point, the majority of CXRs were classed as normal (Figure 3C). At each time point, no differences were detected between treatments $(P>0.44)$. There was also no indication in either treatment arm of a time effect on CXRs $(P>0.11)$. In all 14 patients (9 EC-T; 5 EC-GT) developed abnormal CXRs. In three, the CXR change was possible cardiomegaly/cardiac failure. Only one of these patients had a corresponding change in LVEF (increasing from $60 \%$ at baseline to $81 \%$ !) In two patients, changes were because of infection, one of these with a reported suggestion of pulmonary fibrosis. The reported possible pulmonary fibrosis at 6 months post-chemotherapy was, 2 months later, confirmed as pulmonary metastases. The second patient with a reported possible infection had reduced pulmonary function at the time of the abnormal CXRs.

\section{Hepatic function results}

Overall 99\% of baseline AST results and 94\% of baseline ALT results were normal (Figure $3 \mathrm{D}$ and $\mathrm{E}$ ). Subsequent time points showed normal rates drop slightly to $88 \%$ for AST and $75 \%$ for ALT. Abnormal results were: grade $1=42 \%, 2=50 \% 3=8 \%$ for AST and grade $1=64 \%, 2=18 \%$ and $3=18 \%$ for ALT. At three time points, no treatment differences were detected $(P>0.99$ AST, $P>0.10$ ALT). A higher abnormal rate was detected in EC-GT patients at post-chemotherapy $(P=0.03$ AST, $P=0.003$ ALT).
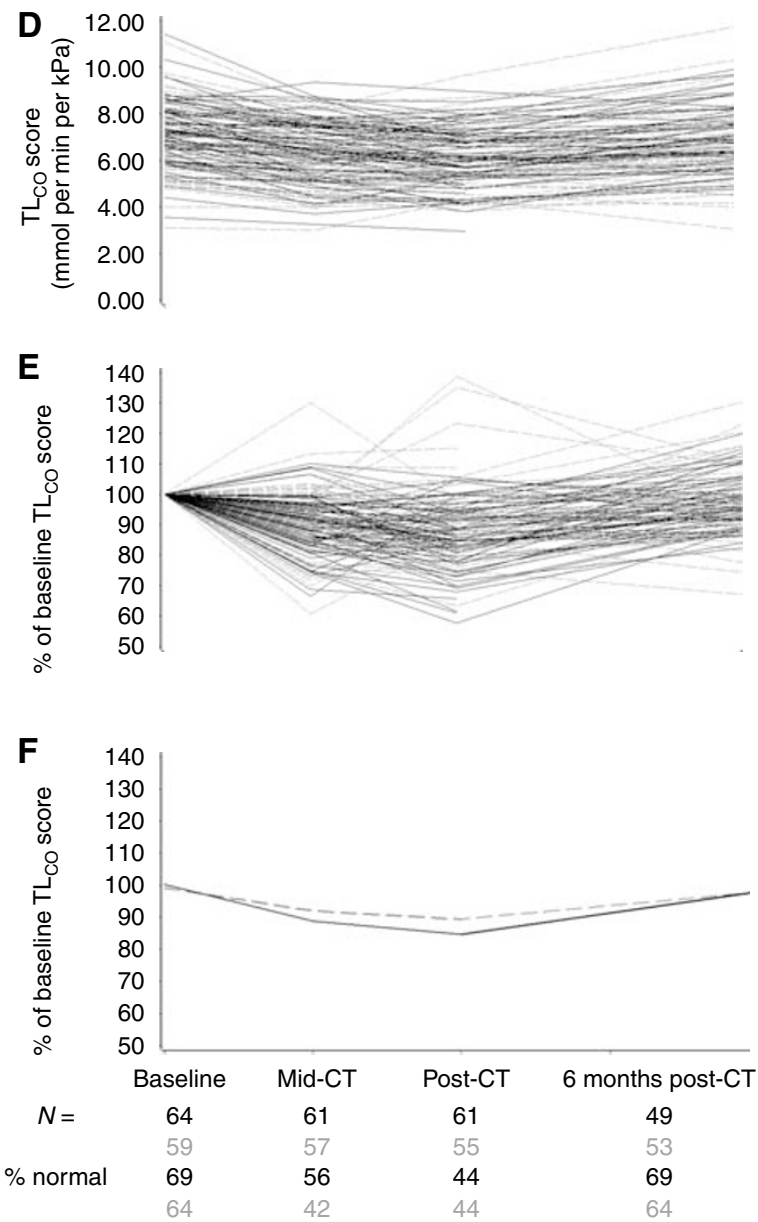

Figure 2 Pulmonary function levels over time (GREY dashed =EC-T patients, BLACK solid = EC-GT patients). (A) FVC levels. (B) FVC levels as percent of patient baseline level. (C) Average FVC levels over time for each treatment arm, predicted by random effects model. (D) $T L_{C O}$ levels. (E) TLCo levels as percent of patient baseline level. $(\mathbf{F})$ Average $\mathrm{TL}_{\mathrm{CO}}$ levels over time for each treatment arm, predicted by random effects model. 

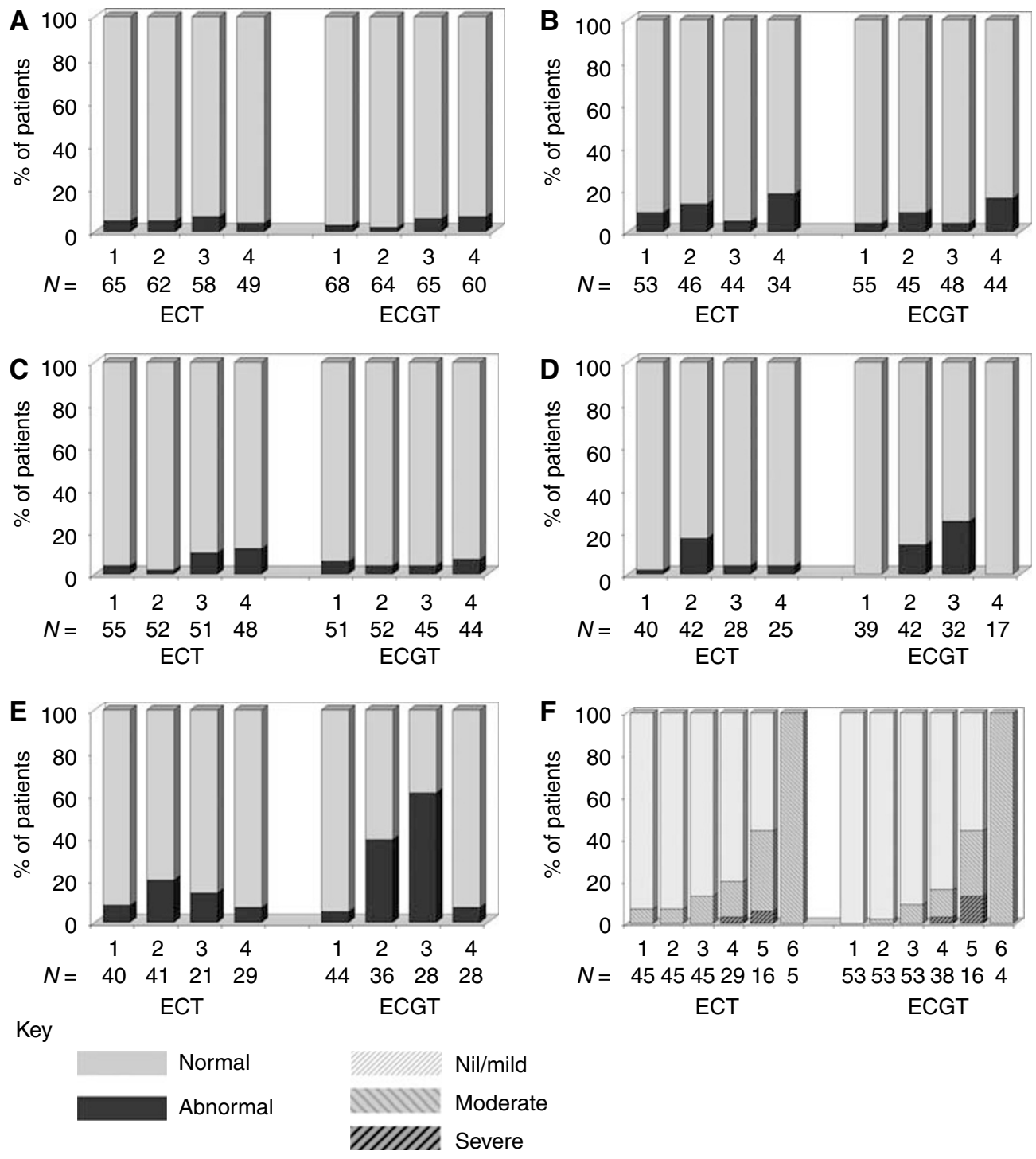

Figure 3 Pulmonary, Cardiac, Chest and Hepatic tests over four time points. Weekly RT toxicity. (A) ECHO/MUGA. (B) ECG. (C) Chest X-ray. (D) AST. (E) ALT. (F) Radiotherapy acute skin toxicity.

There was no change over time in EC-T patients $(P=0.09$ AST, $P=0.32$ ALT) but a significant time effect in EC-GT patients $(P=0.001$ AST, $P<0.0001$ ALT) highlighting more abnormal levels at mid- and post-chemotherapy time points.

AST became abnormal in 15 patients (six EC-T, nine EC-GT) throughout treatment. In 13 patients with abnormal AST at mid-chemotherapy, none required dose reductions and only two dose delays (one in cycle 5 (reason not stated) and one in cycle 5 (for myelosuppression/neutropenia and oral/GI tract toxicity) and cycle 6 (for infection)) during the second half of their treatment regimen. All bar one patient received all their eight chemotherapy cycles (one only receiving five cycles because of an allergic reaction).

In 28 patients ( 8 EC-T, 20 EC-GT) ALT became abnormal during treatment. 22 of these were at mid-chemotherapy. Seven had dose reductions in the second half of their chemotherapy (13 cycles in total). Main reasons were neuropathy, arthralgia and myalgia (most commonly the latter two stated together). Three patients had dose delays in the second half of their chemotherapy (three cycles in total). The reasons were myelosupression/neutropenia, fatigue and a not stated reason. All 22 patients received all their eight chemotherapy cycles.

There was no association between elevated liver enzymes and abnormal FEV, FVC or $\mathrm{TL}_{\mathrm{CO}}$ levels, nor ECHO/MUGA, ECG or CXR results.

\section{Acute skin toxicity results}

One hundred twenty-two of the 135 patients (92\%) received radiotherapy. In 98 (83\%) (45 EC-T, 53 EC-GT), weekly acute skin toxicity was recorded. Toxicity was nil/mild in $87 \%$, moderate in $12 \%$ and severe in $1 \%$. Skin toxicity increased with time in each treatment arm (both $P<0.0001$, Figure 3F), but there was no difference between the chemotherapy groups at any time $(P>0.33)$.

\section{Deaths}

With a median follow-up of 48 months, 25 of 135 patients have died $(19 \%)$. None were attributable to tAnGo treatment. 


\section{DISCUSSION}

The tAnGo trial addresses the addition of gemcitabine to a block sequential anthracycline-taxane regimen for improvement of DFS. Case reports and retrospective series describing a potential problem of pulmonary toxicity from gemcitabine, particularly in proximity to radiotherapy, led us to undertake a systematic prospective quantitative substudy to assess pulmonary function by $\mathrm{FEV}_{1} / \mathrm{FVC}$ measurement, and carbon monoxide diffusion tests. Only $\mathrm{TL}_{\mathrm{CO}}$ was significantly affected by chemotherapy, with a small reduction in both treatment arms, and more so with EC-GT. The majority of this effect occurred during the EC chemotherapy. Six months after treatment, $\mathrm{TL}_{\mathrm{CO}}$ had recovered in both arms.

The effect of anthracycline and cyclophosphamide on pulmonary function has not been well documented until now. A significant reduction in $\mathrm{DL}_{\mathrm{CO}}$ (see Appendix) has been demonstrated in patients with lung cancer following carboplatin/gemcitabine (Maas et al, 2003) or carboplatin/paclitaxel (Dimopoulou et al, 2002). In the tAnGo DSS, we saw a significantly greater drop in $\mathrm{TL}_{\mathrm{CO}}$ levels for EC-GT patients than EC-T patients $(P=0.02)$ but most of this difference had emerged during the EC phase of treatment. By the end of chemotherapy though, equal proportions of patients on the treatment arms were classed as normal, and recovery for all patients appeared complete by 6 months post-chemotherapy. There was no increase in reported pulmonary AEs. A third of the tAnGo DSS patients had dyspnoea recorded as an AE, in $9 \%$ of cycles. The majority was CTC grade 2 .

The rate of cardiac dysfunction in this substudy was comparable with that in CALGB9344 (Henderson et al, 2003) where clinically important cardiac dysrhythmias, congestive heart failure, changes in LVEFs, or any other heart symptoms regardless of any possible relationship to treatment occurred in up to $2 \%$ of patients during treatment and was not significantly different between those who did and those who did not receive paclitaxel. Congestive heart failure was observed during protocol therapy in four $(<1 \%)$ and six $(<1 \%)$ patients and during post-treatment follow-up in 23 (1\%) and $27(2 \%)$ patients randomly assigned to CA (four cycles of cyclophosphamide $600 \mathrm{mg} \mathrm{m}^{-2}$ plus doxorubicin 60,75 or $\left.90 \mathrm{mg} \mathrm{m}^{-2}\right)$ alone and CA plus paclitaxel $\left(175 \mathrm{mg} \mathrm{m}^{-2}\right)$, respectively. In the NSABP-B28 trial (four cycles of cyclophosphamide $600 \mathrm{mg} \mathrm{m}^{-2}$ plus doxorubicin $60 \mathrm{mg} \mathrm{m}^{-2}$ followed by four cycles paclitaxel $225 \mathrm{mg} \mathrm{m}^{-2}$ or no paclitaxel) the incidence of grade 3 or higher cardiac dysfunction either during or subsequent to therapy was $1.0 \%$ in the control and $0.9 \%$ in the experimental arm (Mamounas et al, 2005). The variation in cardiac function in different institutions involved in the tAnGo DSS was a noticeable feature, as was the fact that some patients in whom echocardiography was recorded as abnormal were also shown to have increased LVEF. Although recording of LVEF gives some useful information, it must be remembered that, as with all tests, it has limitations and does not substitute for appropriate liaison with cardiologists when required.

Transient elevation of transaminases were seen in both treatment groups of the tAnGo DSS with significantly more abnormal levels in EC-GT patients post-chemotherapy (AST $P=0.03$, ALT $P=0.003$, respectively), although the majority of these were low grade. The effect of gemcitabine on transaminases is well described and is a dose limiting toxicity at higher doses of gemcitabine (Fossella et al, 1997). Liver enzymes returned to normal by 6 months post-chemotherapy in all bar one EC-T patient with an abnormal AST and four patients (2 EC-T, 2EC-GT) with abnormal ALT levels. The long-term sequelae of disturbances of transaminases are unknown. There was no correlation between increases in liver enzymes and other toxicities, nor any difference in received dose intensity between patients with and without elevated liver enzymes during treatment (median dose intensity 96 and $98 \%$ respectively, $P=0.43$ ).

Gemcitabine has been reported to give rise to a radiation recall phenomenon when used in doses of $600 \mathrm{~m} \mathrm{~m}^{-2}$ and higher (Jeter et al, 2002). However, the tAnGo DSS showed no exacerbation of radiotherapy-related skin toxicity in EC-GT patients when compared with EC-T patients.

The requirement for large adequately powered trials of adjuvant treatment in breast cancer precludes comprehensive testing of all patients for all potential side effects. The concept of detailed safety substudies is well established in endocrine therapy trials (Eastell et al, 2006; Coleman et al, 2007) and detailed toxicity monitoring was performed in the CALGB9344 trial in which complete blood counts were obtained two times weekly, and all toxicities of grade 2 or more were collected on the first 325 patients enrolled. After the Data and Safety Monitoring Board reviewed this data, only toxicities of grades 3 or higher were recorded (Henderson et al, 2003). In the 135 tAnGo DSS patients, there was good protocol compliance especially with respect to the less standard procedures of LVEF monitoring and pulmonary function testing, for which 97 and $91 \%$ of patients respectively had three or more of the required tests and 86 and $76 \%$ respectively had all required time points. Somewhat surprisingly what might be considered more routine testing of transaminases was achieved less frequently.

In conclusion, the tAnGo DSS was undertaken to monitor the introduction of gemcitabine into adjuvant chemotherapy regimen for breast cancer. Both tAnGo treatments appear equally well tolerated, only causing mild to modest reduction in pulmonary function, which recovered completely by 6 months. Gemcitabine caused increased transaminase abnormalities of no clinical significance. This DSS clearly demonstrates that the addition of Gemcitabine to paclitaxel after epirubicin and cyclophosphamide for treatment of early breast cancer is safe. The DSS provides a useful means of detailed safety assessment for the addition of new agents into adjuvant treatment.

\section{ACKNOWLEDGEMENTS}

Contributions were made by Addenbrooke's Hospital, Cambridge; Christie Hospital, Manchester; City Hospital, Birmingham; Clatterbridge Centre for Oncology, Wirral; Cookridge Hospital, Leeds; Crosshouse Hospital, Kilmarnock; Derriford Hospital, Plymouth; King George Hospital, Ilford; Northampton General Hospital, Northampton; Oldchurch Hospital, Romford; Peterborough District Hospital, Peterborough; Poole Hospital, Poole; Queen Elizabeth Hospital, Birmingham; Royal Bournemouth Hospital, Bournemouth; Singleton Hospital, Swansea; St James's University Hospital, Leeds; The James Cook University Hospital, Middlesbrough; Thornbury Hospital, Sheffield; Western General Hospital, Edinburgh; Western Infirmary, Glasgow; Weston Park Hospital, Sheffield. CR UK TU, Birmingham: Helen Howard, Shrushma Loi, Manwinder Atwal SCTN, Edinburgh: Liz Foster, Michelle McDermaid NYCTRU, Leeds: Stephanie Pollard, Catherine Watson, Alex Walker, Kerry Landels City Hospital, Birmingham: David Parr Warwick CTU, Warwick: Louise Hiller, Janet Dunn.

\section{REFERENCES}

Akrivakis K, Schmid P, Flath B, Schweigert M, Sezer O, Mergenthaler HG, Possinger K (1999) Prolonged infusion of gemcitabine in stage I. V. breast cancer: a phase I study. Anticancer Drugs 10: 525-531
Blackstein M, Vogel CL, Ambinder R, Cowan J, Pearce P, Iglesias J (1997) Phase II study of gemcitabine in patient with metastatic breast cancer. Eur J Cancer 33(Suppl. 8): S149 
Bonadonna G, Zambetti M, Moliterni A, Gianni L, Valagussa P (2004) Clinical relevance of different sequencing of doxorubicin and cyclophosphamide, methotrexate, and fluorouracil in operable breast cancer. J Clin Oncol 22(9): $1614-1620$

Carmichael J, Possinger K, Phillip P, Beykirch M, Kerr H, Walling J, Harris Al (1995) Advanced breast cancer: a phase II trial with gemcitabine. J Clin Oncol 13(11): 2731-2736

Coleman RE, Banks LM, Girgis SI, Kilburn LS, Vrdoljak E, Fox J, Cawthorn SJ, Patel A, Snowdon CF, Hall E, Bliss JM, Coombes RC (2007) Skeletal effects of exemestane on bone-mineral density, bone biomarkers, and fracture incidence in postmenopausal women with early breast cancer participating in the Intergroup Exemestane Study (IES): a randomised controlled study. Lancet Oncol 8(2): 119-127

Colomer R, Llombart A, Lluch A, Ojeda B, Barnadas A, Caranana V, Fernandez Y, De Paz L, Guillem V, Alonso S (2000) Paclitaxel/ gemcitabine administered every two weeks in advanced breast cancer: preliminary results of a phase II trial. Semin Oncol 27(1 Suppl 2): 20-24

Dimopoulou I, Galani H, Dafni U, Samakovli A, Roussos C, Dimopoulos MA (2002) A prospective study of pulmonary function in patients treated with paclitaxel and carboplatin. Cancer 94(2): 452-458

Early Breast Cancer Trialists' Collaborative Group (EBCTCG) (2005) Effects of chemotherapy and hormonal therapy for early breast cancer on recurrance and 15-year survival: an overview of the randomised trials. Lancet 365(9472): $1687-1717$

Eastell R, Hannon RA, Cuzick J, Dowsett M, Clack G, Adams JE (2006) Effect of an aromatase inhibitor on bmd and bone turnover markers: 2-year results of the Anastrozole, Tamoxifen, Alone or in Combination (ATAC) Trial. J Bone Miner Res 21(8): 1215-1223

Fossella FV, Lippman SM, Shin DM, Tarassoff P, CalayagJung M, PerezSoler R, Lee JS, Murphy WK, Glisson B, Rivera E, Hong WK (1997) Maximum-tolerated dose defined for single-agent gemcitabine: a phase I dose-escalation study in chemotherapy-naive patients with advanced non-small-cell lung cancer. J Clin Oncol 15(1): 310-316

Gupta N, Ahmed I, Steinberg H, Patel D, Nissel-Horowitz S, Mehrotra B (2002) Gemcitabine-induced pulmonary toxicity: case report and review of the literature. Am J Clin Oncol 25(1): 96-100

Henderson IC, Berry DA, Demetri GD, Cirrincione CT, Goldstein LJ, Martino S, Ingle JN, Cooper MR, Hayes DF, Tkaczuk KH, Fleming G, Holland JF, Duggan DB, Carpenter JT, Frei E, Schilsky RL, Wood WC, Muss HB, Norton L (2003) Improved outcomes from adding sequential paclitaxel but not from escalating doxorubicin dose in an adjuvant chemotherapy regimen for patients with node-positive primary breast cancer. J Clin Oncol 21(6): 976-983

Jeter MD, Janne PA, Brooks S, Burstein HJ, Wen P, Fuchs CS, Loeffler JS, Devlin PM, Salgia R (2002) Gemcitabine-induced radiation recall. Int J Radiation Oncol Biol Phys 53(2): 394-400

Kroep JR, Giaccone G, Voorn DA, Smit EF, Beijnen JH, Rosing H, van Moorsel CJA, van Groeningen CJ, Postmus PE, Pinedo HM, Peters GJ (1999) Gemcitabine and paclitaxel: pharmacokinetic and pharmacodynamic interactions in patients with non-small-cell lung cancer. J Clin Oncol 17: 2190-2197

\section{Appendix}

$\mathrm{TL}_{\mathrm{CO}}$ (reported in $\mathrm{mlmin} \mathrm{kPa}^{-1}$ ) and $\mathrm{DL}_{\mathrm{CO}}$ (reported in $\mathrm{ml}^{-1} \mathrm{~min}^{-1} \mathrm{~mm} \mathrm{Hg}$ ) measure the same function and are related by a conversion factor $\left(\mathrm{TL}_{\mathrm{CO}}=0.335 \mathrm{DL}_{\mathrm{CO}}\right)$.
Levine MN, Pritchard KL, Bramwell VHC, Shepherd LE, Tu DS, Paul N (2005) Randomized trial comparing cyclophosphamide, epirubicin, and fluorouracil with cyclophosphamide, methotrexate, and fluorouracil in premenopausal women with node-positive breast cancer: Update of National Cancer Institute of Canada Clinical Trials Group Trial MA5. J Clin Oncol 23(22): 5166-5170

Maas KW, van der Lee I, Bolt K, Zanen P, Lammers JWJ, Schramel FMNH (2003) Lung function changes and pulmonary complications in patients with stage III non-small cell lung cancer treated with gemcitabine/ cisplatin as part of combined modality treatment. Lung Cancer 41(3): $345-351$

Mamounas EP, Bryant J, Leinbersky B, Fehrenbacher L, Sedlacek SM, Fisher B, Wickerham DL, Yothers G, Soran A, Wolmark N (2005) Paclitaxel after doxorubicin plus cyclophosphamide as adjuvant chemotherapy for node-positive breast cancer: results from NSABP B-28. J Clin Oncol 23(16): 3686-3696

Mamounas EP, Bryant J, Lembersky BC, Fisher B, Atkins JN, Fehrenbacher L, Raich PC, Yothers G, Soran A, Wolmark N (2003) Paclitaxel following doxorubicin/cyclophosphamide as adjuvant chemotherapy for nodepositive breast cancer: results from NSABP B-28. Proc Am Soc Clin Oncol 22(4)

McGinn CJ, Shewach DS, Lawrence TS (1996) Radiosensitizing nucleosides. J Natl Cancer Inst 88(17): $1193-1203$

Poole CJ, Earl HM, Hiller L, Dunn JA, Bathers S, Grieve RJ, Spooner DA, Agrawal RK, Fernando IN, Brunt AM, O'Reilly SM, Crawford SM, Rea DW, Simmonds P, Mansi JL, Stanley A, Harvey P, McAdam K, Foster L, Leonard RCF, Twelves CJ (2006a) Epirubicin and cyclophosphamide, methotrexate, and fluorouracil as adjuvant therapy for early breast cancer. New Engl J Med 355(18): 1851 - 1862

Poole CJ, Perren T, Gawande S, Ridderheim M, Cook J, Jenkins A, Roychowdhury D (2006b) Optimized sequence of drug administration and schedule leads to improved dose delivery for gemcitabine and paclitaxel in combination: a phase I trial in patients with recurrent ovarian cancer. Int J Gynecol Cancer 16(2): 507-514

Quanjer PH (ed) (1993) ERS 1993 update. Eur Respir J 6: S16

Sanchez P, Medina MB, Mohedano N, Jaen A, Porras I, Gonzalez E, Fernandez M, Lozano A (1998) Results from a phase II study of gemcitabine in combination with paclitaxel in metastatic breast cancer. Ann Oncol 9(Suppl 4): 77P

Sara S, King E, Unger M, Langer C (2000) Retrospective analysis of gemcitabine induced pulmonary toxicity: critical management issues. Proc Am Soc Clin Oncol 19: 2402

Spielmann M, Kalla S, LlombartCussac A, Espie M, Namer M, Ferrero JM, Cuvier C, Fumoleau P, Ponzio A, Kayitalire L, Pouillart P (1997) Activity of gemcitabine in metastatic breast cancer patients previously treated with anthracycline-containing regimens. Eur J Cancer 33(Suppl. 8): S149

Trodella L, Granone P, Valente S, Turriziani A, Macis G, Corbo GM, Margaritora S, Cesario A, D'Angelillo RM, Gualano G, Ramella S, Galetta D, Cellini N (2002) Phase I trial of weekly gemcitabine and concurrent radiotherapy in patients with inoperable non-small-cell lung cancer. J Clin Oncol 20: 804-810 